Journal of EnvirOnmental Sciences
JOESE 5
ISSN 2090-9233
Journal homepage http://Joese.mans.edu.eg

Original Article

\title{
Decolorization of Textile Wastewater Using Fabricated Poly Acrylonitrile (PAN) Nanoparticles
}

\author{
Omnya A. El-Batrawy ${ }^{1 *}$, Mahmoud S. Ibrahim ${ }^{1}$, Hala Fakhry ${ }^{1,2}$ and M. R. El-Aassar ${ }^{2}$ \\ ${ }^{I}$ Environmental Sciences Department, Faculty of Science, Damietta University, New Damietta City, Damietta, 34517, Egypt. \\ ${ }^{2}$ Polymer Materials Research Department, Advanced Technology and New Materials Researches Institute, City of Scientific Researches and \\ Technological Applications, New Borg El-Arab City, Alexandria, 21934 Egypt.
}

\begin{tabular}{|c|c|}
\hline Article Info & Abstract \\
\hline $\begin{array}{l}\text { Keywords: } \\
\text { Dye removal } \\
\text { Basic Red } 46 \\
\text { Batch Mode Experiments } \\
\text { Adsorption isotherm } \\
\text { Kinetic Models }\end{array}$ & $\begin{array}{l}\text { Water contamination is not only influence human health and environment, but it has also } \\
\text { effects on social and economic costs. Textile wastewater is considered to be one of the most } \\
\text { dangerous types of water contaminants as it consists of mixture of pigments, dyes and different } \\
\text { types of organic contaminants. Nanotechnology offers novel functional materials in the area of } \\
\text { wastewater treatment especially dye removal. Polyacrylonitrile (PAN) nanoparticles considered to } \\
\text { be one of the most promising prepared materials in the field of dye removal. PAN nanoparticles } \\
\text { was prepared by precipitation polymerization technique in an alcoholic aqueous solution (water: } \\
\text { ethanol) and was characterized using scanning electron microscope (SEM), Fourier Transfer } \\
\text { infrared spectrophotometer (FT-IR) and Thermal Gravimetric Analysis (TGA). Basic Red } 46 \text { (BR } \\
46 \text { ) dye is a cationic dye which is used as a model of contaminant due to its extensive use in } \\
\text { textile industry. The processing parameters affecting on the adsorption of BR } 46 \text { onto the } \\
\text { prepared PAN nanoparticles have been optimized through a batch mode experiments. } \\
\text { The maximum removal percentage of the selected dye was } 62.4 \% \text { recorded after } 240 \text { min } \\
\text { equilibrium time using } 0.05 \mathrm{~g} \text { from PAN nanoparticles and with } 5 \text { ppm initial dye concentration. } \\
\text { As the experimental results proved that the increment in material dosage from } 0.01 \text { to } 0.5 \mathrm{~g} \\
\text { enhanced the dye removal percentage from } 43.6 \% \text { up to } 85 \% \text {. Meanwhile, the improvement in } \\
\text { initial dye concentrations had negative impact on the adsorption process onto the prepared } \\
\text { powdered material, as it decreased from } 82.3 \text { to } 11.85 \% \text { when the initial dye concentration } \\
\text { increased from } 1-100 \text { ppm. The dye adsorption mechanism was investigated through the } \\
\text { application of Langmuir and Freundlich isotherm models on the experimental data. Moreover, the } \\
\text { kinetics of dye adsorption process was tested using the pseudo-first and pseudo-second order } \\
\text { kinetic models. }\end{array}$ \\
\hline
\end{tabular}

\section{Introduction}

Rapid industrialization has resulted in the generation of large amounts of wastewater that affect adversely on environment. Textile wastewater is a mixture of colorants (dyes and pigments) and various organic compounds used as cleaning solvents, plasticizers etc. (Crini and Badot, 2008). Textile wastewater contains colored organic compounds as their color renders them esthetically unacceptable. Color is the first contaminant to be recognized in waste water and cause serious ecological problems (Sharma et al, 2007).

Organic dyes are considered to be one of the most serious and dangerous water contaminants, as they intensively used in a lot of industries as leather goods, paper, cosmetics, textile

\section{*Correspondence author:}

E-mail address:om_elbatrawy@du.edu.eg;om_elbatrawy@hotmail.com Tel.: 01003479359 etc. These dyes which released with the waste effluents undergo chemical changes, decrease dissolved oxygen, increase chemical oxygen demand (COD) and destroy aquatic ecology. Moreover, they cause carcinogenic and genotoxic effects on human life (Prachi et al, 2013). Therefore, the decolorization of toxic organic dyes from wastewater before discharging them into natural water streams has received a great deal of attention recently (Aksakala and Ucun, 2010; El Haddad et al., 2012; Haider et al., 2014; Hu et al., 2017). In recent years, numerous methods as flocculation, adsorption, photo degradation and chemical oxidation have been developed to treat wastewater containing dye stuffs (Ibrahim et al., 2017). Among them, adsorption technique has been recognized as a promising technique due to its high efficiency, simplicity of design, ease of operation as well as the wide suitability for diverse types of dyes (Han et al., 2017). 
Nanotechnology offers novel functional materials, processes and devices with unique activity toward wastewater treatment. Many nano-based environmental technologies are expected to improve or replace various conventional environmental technologies in the near future (Sun et al, 2006, Satapanajaru et al, 2011and Prachi et al, 2013). Generally, nano-polymeric adsorbents have unique adsorptive proprieties and capacities for dye removal (Prachi et al, 2013). Poly acrylonitrile (PAN) are considered to be an outstanding material for environmental applications due to its good mechanical properties, moderate separating properties, unique thermal properties and good solvent resistance (Mahmoodi et $\boldsymbol{a l}, 2011$ and Hadi, 2013). It is also an excellent material in the purification of dyes and heavy metals from wastewater (Musale and Kumar, 2000).

Basic Red 46 (BR 46) dye was used as a contaminant in a synthetic wastewater model as it is used intensively in textile industry; also its release into the environment is of concern due to their toxic, mutagenic and carcinogenic characteristics (Kaouah et al., 2013). The present study is focused on the preparation of PAN nanoparticles through precipitation polymerization technique with the ability to remove BR 46 from aqueous solution. Moreover, the influence of different processing parameters affecting on dye adsorption process onto the prepared PAN nanoparticles will be monitored.

\section{Material and Methods}

\subsection{Materials}

Potassium persulfate $\left(\mathrm{K}_{2} \mathrm{~S}_{2} \mathrm{O}_{8}\right)$ and acrylonitrile (AN) were obtained from $\mathrm{BDH}$ (London, UK). The selected dye; azo dye of Basic Red 46 (BR 46); was obtained from Amria textile factory (Alexandria, Egypt). All other chemicals were of analytical grade and were purchased from Sigma.

\subsection{Preparation of PAN Nanoparticles}

PAN powdered nanoparticles was prepared using simple precipitation polymerization technique in the presence of $\mathrm{K}_{2} \mathrm{~S}_{2} \mathrm{O}_{8}$ as an initiator (El-Aassar, 2013). The polymerization process was done through the dissolution of AN monomers in $0.01 \mathrm{M} \mathrm{K}_{2} \mathrm{~S}_{2} \mathrm{O}_{8}$ alcoholic solution of water: ethanol (1:1) as cosolvent at the room temperature. The total volume of .monomer to the cosolvent is $10 \%$. For completeness of the polymerization process the previous polymerization solution was stirred in a thermostatic water bath for $4 \mathrm{~h}$ at $55^{\circ} \mathrm{C}$. The obtained powder washed by ethanol-water solution repeatedly to dispose of un-reacted monomer and initiator. The gained powder was dried in oven over night at $45^{\circ} \mathrm{C}$ then grinded to the desired mesh size.

\subsection{Preparation of Adsorbate Solution}

Basic Red 46 (BR 46) dye is a cationic dye and its molecular structure was illustrated in Figure 1 (Sarioglu et al., 2007). The used stock dye solution was $100 \mathrm{ppm}$.

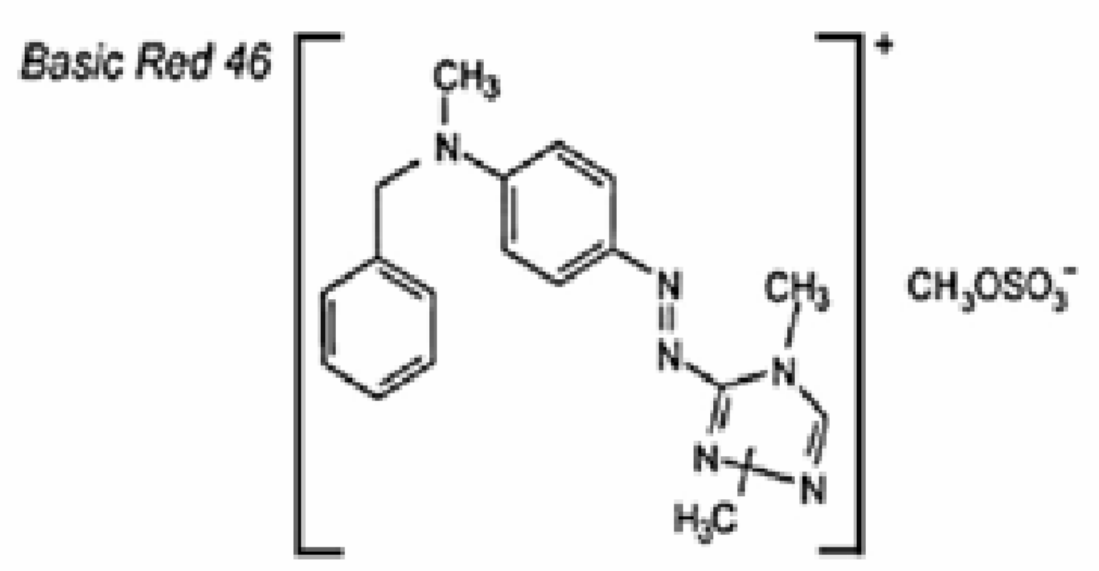

Figure 1: Molecular structure of Basic Red 46 (Sarioglu et al., 2007).

\subsection{Characterization of Prepared PAN Nanoparticles}

\subsubsection{Scanning Electron Microscopic Analysis (SEM)}

The scanning electron microscope (JEOL JSM 6360LA, Japan) images of the prepared PAN nanoparticles were obtained by putting the materials onto carbon tape-attached aluminum SEM holders then; the particles were coated with gold to a few nanometer thicknesses under vacuum.

\subsubsection{Fourier Transform Infrared Spectroscopic Analysis} (FT-IR)

An FT-IR spectrum (Jasco-4100) of the prepared PAN nanoparticles was carried out with a FT-IR spectrometer in the spectral range of $4,000-500 \mathrm{~cm}^{-1}$. 


\subsubsection{Thermo Gravimetric Analysis (TGA)}

A thermo gravimetric analyzer (TGA-50 Shimadzu) was used to carry out the thermal analysis of the prepared PAN nanoparticles. About $6 \mathrm{mg}$ of particles were put in ceramic pans of TGA instrument and the thermal analysis was carried out over the temperature range of $0-600^{\circ} \mathrm{C}$ with $10^{\circ} \mathrm{C} / \mathrm{min}$ heating rate under dry $\mathrm{N} 2$ flow and $10 \mathrm{~mL} / \mathrm{min}$ rate.

\subsection{Batch BR 46 Adsorption Experiments}

A batch process technique was used to evaluate the adsorption behaviour of the prepared PAN nanoparticles through a series of batch adsorption experiments were performed in order to evaluate the prepared PAN nanoparticles as dye removing agent from aqueous solutions. Studies were carried out in triplicate to get concordant results using a batch adsorption technique.

Different processing parameters affecting on the adsorption process of BR 46 onto the prepared PAN nanoparticles such as contact time, initial dye concentration, solution $\mathrm{pH}$, adsorbant dosage and solution temperature had been optimized. The adsorption process mechanism had been studied through the addition of $0.05 \mathrm{~g}$ of the prepared PAN nanoparticles to $20 \mathrm{ml}$ of $10 \mathrm{ppm}$ of BR 46 dye solution. The mixture was shacked at $400 \mathrm{rpm}$ for a predetermined period of time, then, withdrawn the clear supernatant and centrifuged for $15 \mathrm{~min}$ at $15,000 \mathrm{rpm}$. The absorbance of the remaining solutions is measured at a maximum wavelength of $530 \mathrm{~nm}$ using a double beam UV/vis spectrophotometer (Jenway 6305). Figure 2 represents an illustration scheme of dye removal process using PAN Nanoparticles.

The amount of dye adsorption at equilibrium $(\mathrm{mg} / \mathrm{g})$ was calculated from the following equation:

$$
\boldsymbol{q} \boldsymbol{e}=\frac{\left(c_{0}-c_{e}\right) v}{W}
$$

where $\mathrm{C}_{0}$ is the initial dye concentration, $\mathrm{C}_{\mathrm{e}}(\mathrm{mg} / \mathrm{L})$ is the concentration of the used dye at equilibrium, $\mathrm{V}(\mathrm{L})$ is the solution volume and $\mathrm{W}(\mathrm{g})$ is the adsorbent mass.

The removal percentage of the used dye was calculated by the following equation:

$$
\% \text { of dye removal }=\frac{\mathrm{Co}-\mathrm{Ce}}{\mathrm{Co}} * 100
$$

where $\mathrm{C}_{0}$ and $\mathrm{C}_{\mathrm{e}}(\mathrm{mg} / \mathrm{L})$ are the concentrations of dye at the initial and equilibrium stages.

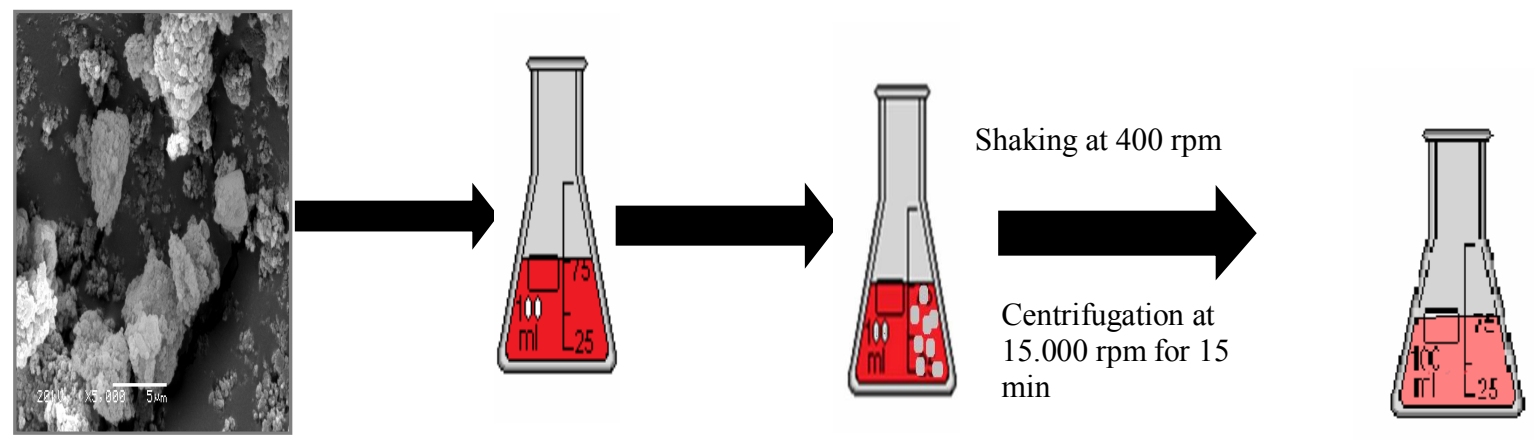
$\begin{array}{lll}\text { PAN Material } & \text { Adsorbate solution }(10 \mathrm{ppm}) & \begin{array}{l}\text { Adsorbate solution+ } \\ \text { Adsorbent }(0.05 \mathrm{gm})\end{array}\end{array} \quad$ Adsorbate solution at $530 \mathrm{~nm}$

Figure 2: An illustration scheme of dye removal process using PAN Material.

\subsection{Kinetic and Equilibrium Behaviors of BR 46 Dye Adsorption Process onto the Prepared PAN Nanoparticles.}

The adsorption process of Basic Red (BR 46) dye onto the prepared PAN particles were investigated using Langmuir and Freundlich equilibrium isotherm models. Moreover, the kinetics of dye adsorption process was tested using the pseudo-first and pseudo-second order kinetic models.

\section{Results and Discussion}

\subsection{Characterization of PAN Powder Nanoparticles}

\subsubsection{Morphological Characterization [Scanning Electron Microscopy (SEM)]}

The morphological structure of the prepared PAN nanoparticles was investigated using scanning electron microscope image (Figure 3). It was so obvious from figure 3that the prepared PAN nanoparticles doesn't have any definite structure, has irregular form with a high degree of heterogeneity; also, from the first look to the figure, it looks like a huge bulk of particles within the micro scale. 


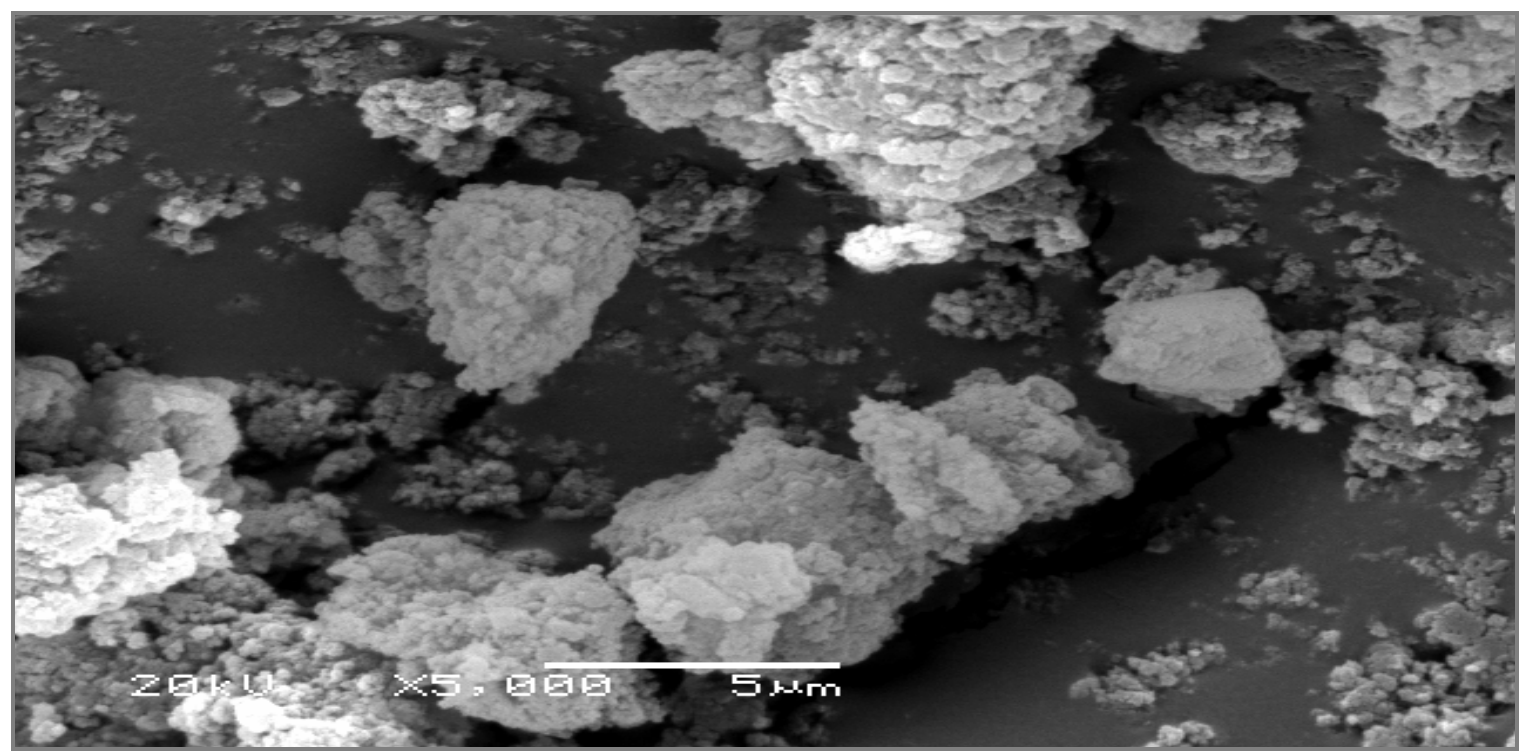

Figure 3: SEM image of the prepared PAN material

\subsubsection{Fourier Transform Infrared Spectroscopic Analysis (FT-IR) Spectra}

FT-IR spectra technique was used to identify the main functional groups that located on the prepared material and responsible for dye adsorption process. Figure 4 showed a broad band at $3471.98 / \mathrm{cm}$ for $(\mathrm{O}-\mathrm{H})$ water bond. Also, the representative band at $2249.07 / \mathrm{cm}$ is attributed to $\mathrm{C} \equiv \mathrm{N}$ bonding. The characteristic band at $1444.73 / \mathrm{cm}$ represents $\mathrm{C}=\mathrm{C}$; however, the identified band $2249.07 / \mathrm{cm}$ is assigned for $\mathrm{C}-\mathrm{H}$. These results confirmed the formation of PAN polymeric material through the presence of its characteristic peaks.

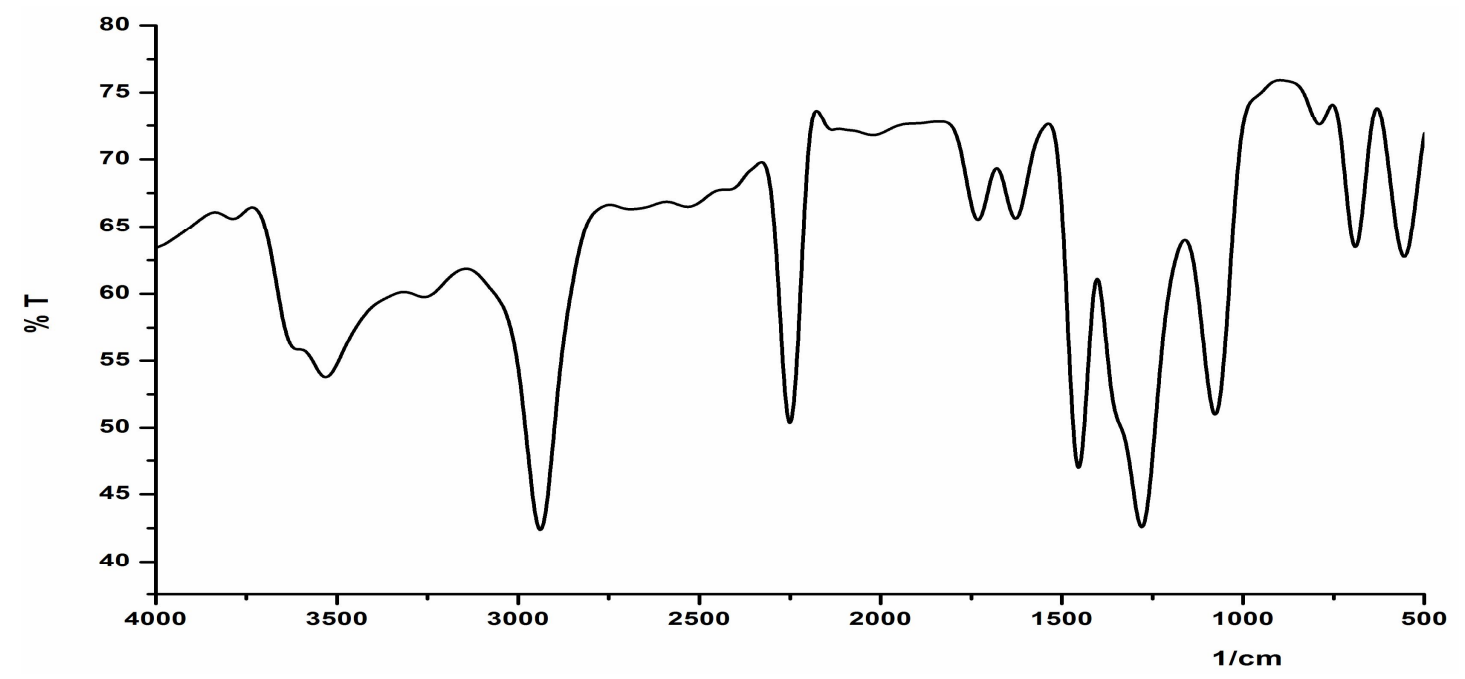

Figure 4: FT-IR spectra of the prepared PAN material.

\subsubsection{Thermo Gravimetric Analysis (TGA) Analysis}

Thermo Gravimetric Analysis (TGA) is a thermal analysis method in which any increasing in material temperature (with constant heating rate) leads to changes in its physical and chemical properties or as a function of time (with constant temperature and/or constant mass loss) (Coats and Redfern, 1963). The main degradation step of PAN nanoparticles began at $27.7^{\circ} \mathrm{C}$ and ended at $295.40^{\circ} \mathrm{C}$ with a percentage of weight losses of $1.172 \%$ which represented the physical water adsorbed onto PAN; this was showed through the first pattern of PAN (Figure 5). The second step of degradation began at $295.40^{\circ} \mathrm{C}$ and ended at $405.93^{\circ} \mathrm{Cwith}$ percentage of weight losses of $7.855 \%$. The last degradation step began at $405.93^{\circ} \mathrm{Cand}$ end at $472.30^{\circ} \mathrm{C}$ with percentage of weight losses of $6.654 \%$. 


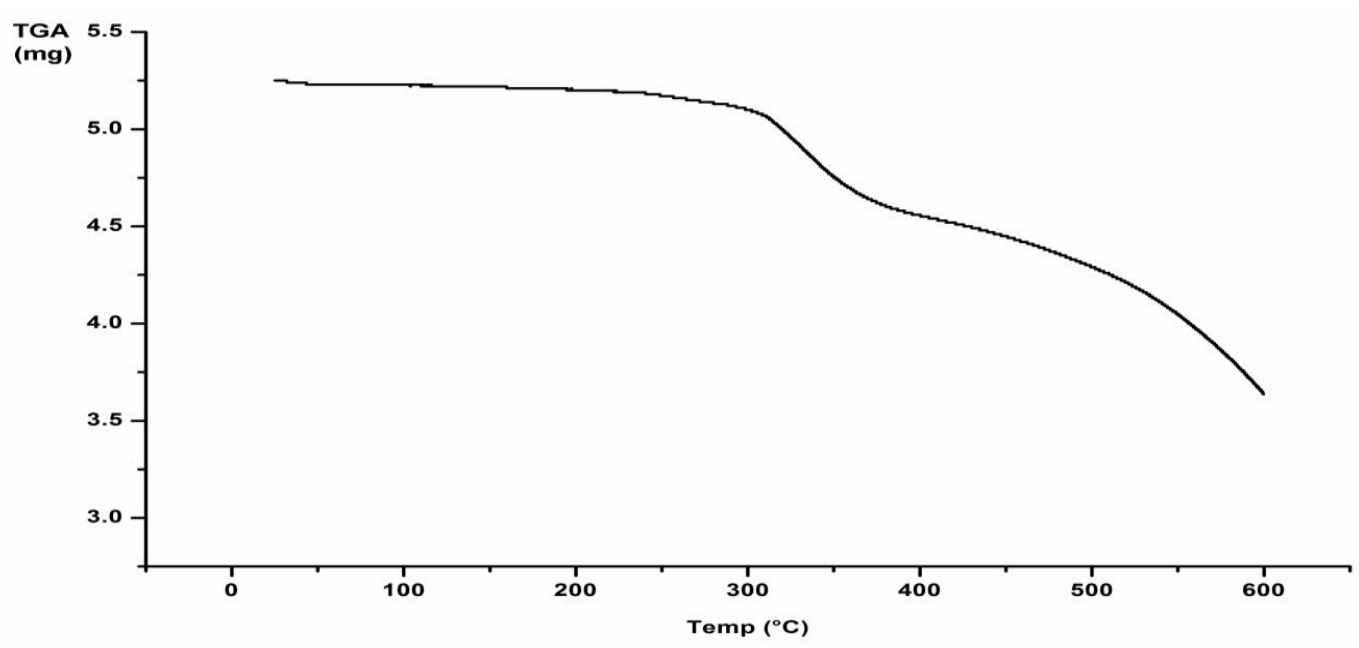

Figure 5: TGA of the prepared PAN material.

\subsection{Decolorization of BR (46) using the Prepared PAN Nanoparticles}

\subsubsection{Effect of BR (46) Initial Concentration}

The removal percentage of dye depends on the initial dye concentration. It was observed from Figure (6) that the Basic Red 46 removal percentage is inversely proportional to the initial dye solution concentration as it decreased from 82.3 to $11.8 \%$ when the dye concentration increased from 1100 ppm using PAN nanoparticles. This behavior might be attributed to the repulsive forces between the dye molecules on the prepared PAN nanoparticles surface and the bulk phase (Crini and Badot, 2008; Salama, 2017). At lower dye concentrations, the ratio between the numbers of dye molecules to the available active sites located on the adsorbent surface is low. However, at high concentration the available sites of adsorption becomes fewer, and hence the percentage removal of dye depends upon concentration of nanopolymeric nanoparticles (El Haddad et al., 2012). Also, the reduction in dye removal might be due to saturation of adsorption active sites on the material surface as the concentration of dye increases (Tiwari et al., 2014).

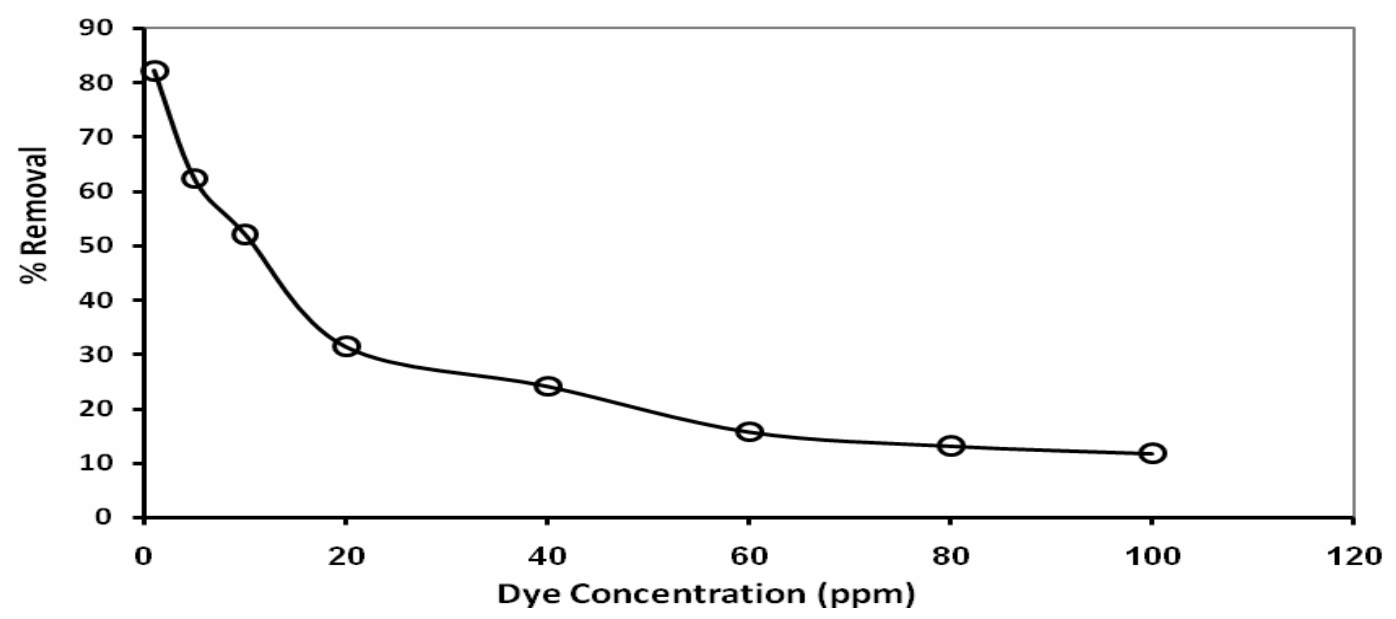

Figure 6: Effect of dye concentration on dye adsorption process onto PAN prepared material (contact time $=240 \mathrm{~min}$, material dosage $=0.05 \mathrm{~g}$, temperature $=25^{\circ} \mathrm{C}$ and $\mathrm{pH}=7$ ).

\subsubsection{Effect of the Contact Time}

The effect of contact time on the adsorption of basic red dye onto the prepared PAN nanoparticles was investigated over 270 min time intervals (Figure 7). The removal of the used dye was increased with increasing contact time between dye and the prepared material at initial dye concentration of $5 \mathrm{mg} / \mathrm{L}$. The removal percentage of dye using PAN nanoparticles increases from $9.2 \%$ up to $62.4 \%$ when the contact time between dye and PAN nanoparticles increase from 5 to 240 minutes. Relatively fast equilibrium has been achieved due to the large amount of available active sites at the surface of the prepared PAN nanoparticles. After the equilibrium time (240 min) slightly increase in the removal percentage had been noticed as the surface of the prepared material almost might be occupied with the dye molecules. It 
was found that, a large number of unoccupied surface active sites are obtainable for adsorption during the first stage, and continuous occupation of these sites decreased the rate of reaction and subsequently reduce adsorption efficacy (Araujo and Teixeira, 1997, Srivastava et al., 2006; Srivastava et al., 2008 and Kalavathy and Miranda, 2010). This behavior might also be due to the aggregation of dye molecules around
PAN particles which might block the migration of dye molecules as the PAN active sites become saturated and improve resistance of diffusion of dye molecules into the adsorbents (EL-kady et al., 2018). Similar trend was obtained in the adsorption of MB on sulfonic acid group modified MIL101(Luo et al., 2016).

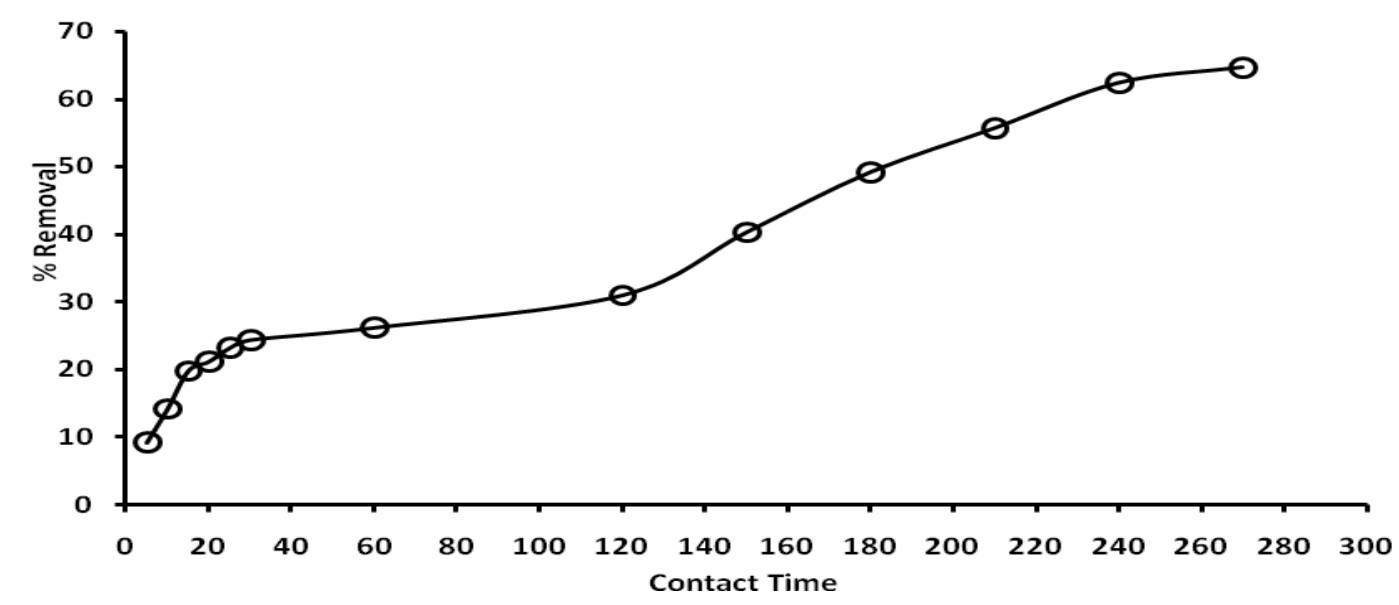

Figure 7: Effect of Contact Time on dye adsorption process onto PAN prepared material (Initial due concentration $=5 \mathrm{ppm}$, material dosage $=0.05 \mathrm{~g}$ and $\mathrm{pH}=7$ ).

\subsubsection{Effect of PAN Adsorbent Dosage}

The effect of the prepared PAN nanoparticles dosage on the percentage of dye removal was studied after $240 \mathrm{~min}$ (Figure 8), different weights of PAN nanoparticles $(0.01,0.05$, $0.1,0.2,0.3,0.4$ and $0.5 \mathrm{~g}$.) was used at equilibrium. The BR 46 percentage removal was increased with increasing adsorbent doses due to the occurrence of more active sites on the PAN surface which increase the active functional groups at higher adsorbent dosages. The maximum dye removal percentage of $88.6 \%$ was recorded using $0.5 \mathrm{~g}$ of PAN nanoparticles. Moreover, the decrease of sorption capacity with raising material dose might be due to the presence of more active sites on the material surface as adsorption capacity increase in the first stage of adsorption, but further increase in material dose saturates the adsorbents and there was a steady state (Tiwari et al., 2014). It is as a result of dye molecules aggregation on the adsorption sites that decrease the adsorption efficiency. Also, there will be overlapping of adsorption sites because of overcrowding of material particles (Gorza et al., 2017). The same behaviour was also illustrated by Deniz and Karaman (2011) as they found that, the removal percentage of BR 46 increased with the increase of material dose.

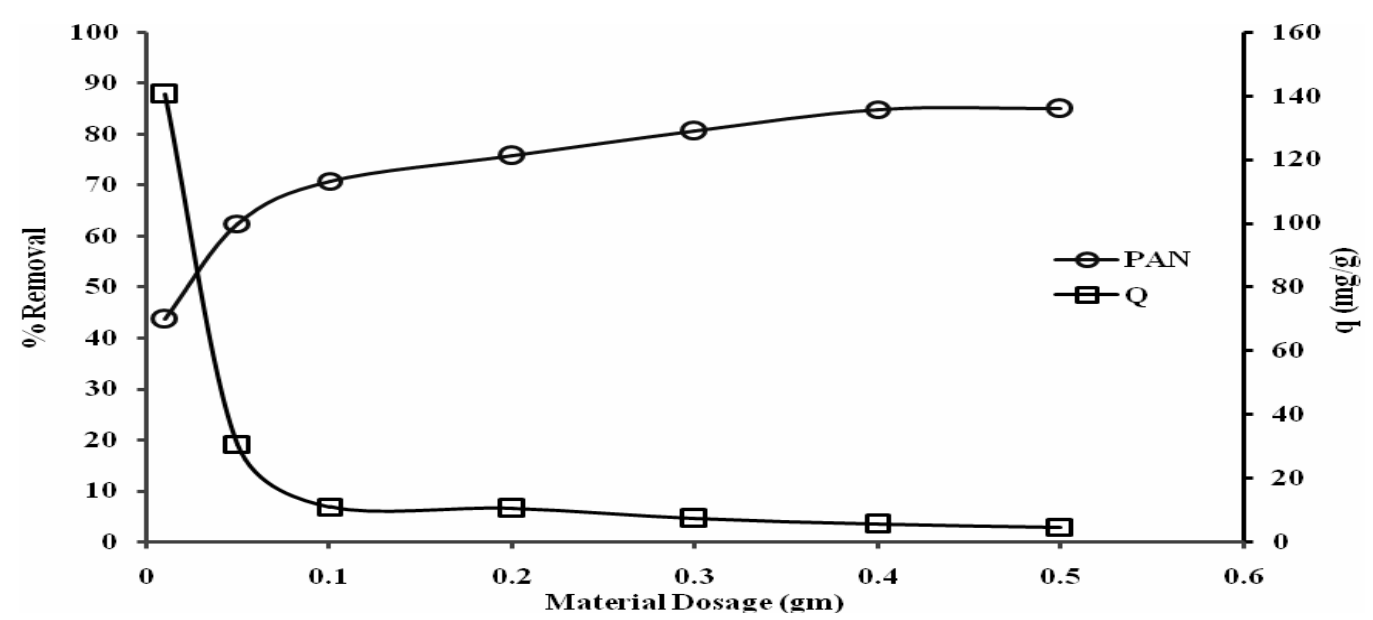

Figure 8: Effect of adsorbent dosage (contact time $=240 \mathrm{~min}$; dye concentration= $5 \mathrm{ppm}$ and $\mathrm{pH}=7$ ). 


\subsubsection{Effect of Solution $\mathrm{pH}$ on Dye Adsorption}

The dye solution $\mathrm{pH}$ plays an important role in the adsorption process in the field of dye wastewater treatment (Lou et al., 2018). It was indicated that the $\mathrm{pH}$ significantly affected the extent of adsorption of dye and the removal of BR 46. The removal percentage of BR 46 onto prepared PAN nanoparticles increased from $40.7 \%$ to $96.3 \%$ when the solution $\mathrm{pH}$ rose from 1 to 13 (Figure 9). This behavior might be attributed to the cationic nature of the used dye which has naturalization trend in alkaline media better than acidic medium (Janaki et al., 2012). In basic solution the electrostatic interaction between the dye cation and PAN was increased as the materials surfaces were negatively charged due to the presence of excess $\mathrm{OH}^{-}$(EL Alouani et al., 2018), however in acidic solution the presence of $\mathrm{H}^{+}$may compete with the dye cations, which results in lower adsorption of dye on the prepared material chain (Hameed and Ahmad 2009). This is agreed well with (Karim et al., 2009), as they mention that, the adsorption capacity of BR46 onto the prepared clay significantly increased when the dye solution $\mathrm{pH}$ increased from 9.5 to 12 . In basic conditions, the clay surface which has a negative charge favours the BR46 adsorption and subsequently, the amount of BR46 adsorbed onto the prepared clay decreased with the decrease of $\mathrm{pH}$.

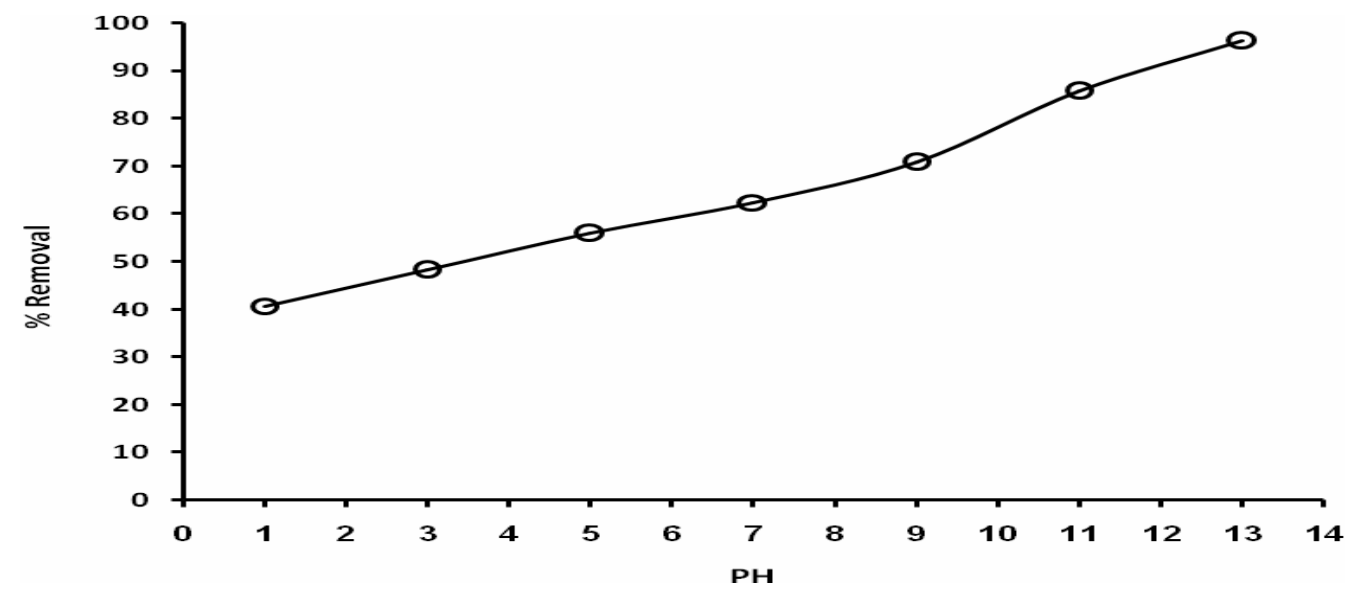

Figure 9: Effect of solution $\mathrm{pH}$ on dye adsorption (contact time $=240 \mathrm{~min}$; adsorbant dosage $=0.05 \mathrm{~g}$ and dye concentration $=5 \mathrm{ppm}$ ).

diffusion rate of dye particles through the outer layer and in the internal pores of the material particle, as the solution viscosity decreased (Wua et al., 2011). Moreover the equilibrium capacity of the prepared materials will be changed by changing temperature (Al-Qodah, 2000). Also, with increasing temperature the motion of dye molecules increased (Alkan and Dogan, 2003).

\subsubsection{Effect of Temperature on Dye Adsorption:}

The effect (influence) of temperature on the adsorption rate of BR46 on PAN nanoparticles was investigated at 25, 35, 45 and $75^{\circ} \mathrm{C}$. The percentage of dye removal increased from 50.1 to $85 \%$ when temperature of the solution was increased from 25 to $75^{\circ} \mathrm{C}$, indicating that the process is an endothermic (Figure 10). Raising temperature is expected to increase the

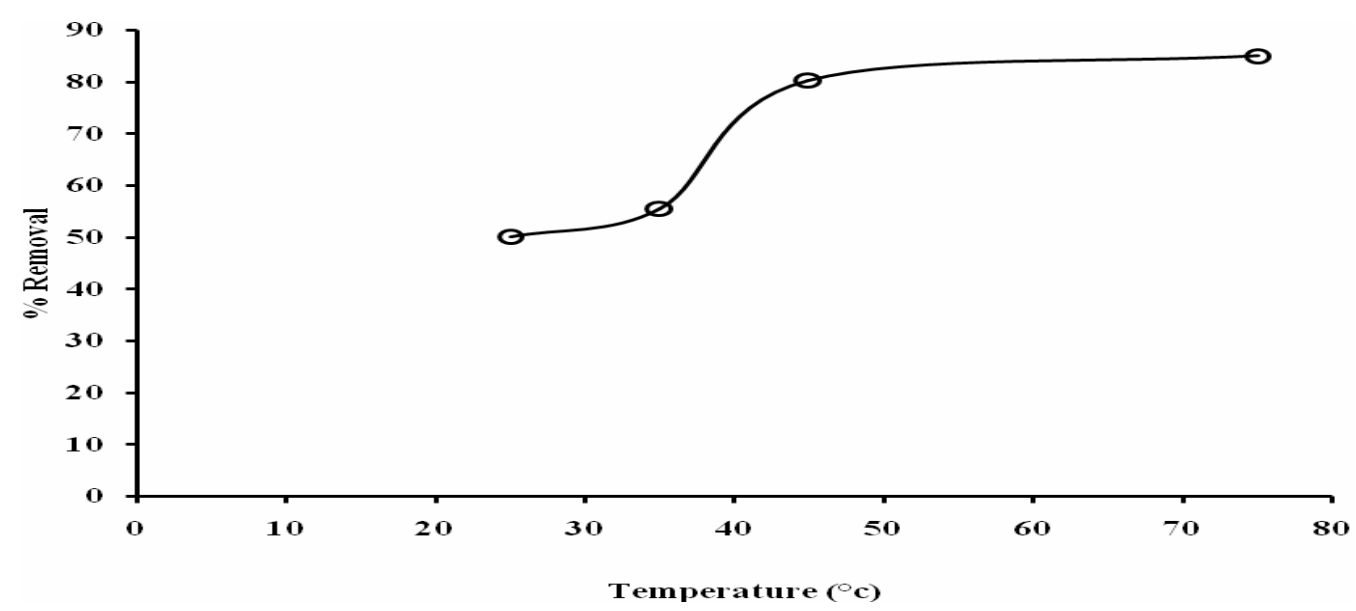

Figure 10: Effect of Temperature on dye adsorption (contact time $=240 \mathrm{~min}$; adsorbant dosage $=0.05 \mathrm{~g}$ and dye concentration $=5 \mathrm{ppm})$. 
Journal of Environmental Sciences, 2018; Vol. 47, No. 3-4 : 75-87

\subsection{Adsorption Equilibrium}

When the adsorption process reached the equilibrium, the process which described the distribution of molecules between liquid and solid phase called adsorption isotherms or adsorption equilibrium (Abu-Saied et al., 2013). Adsorption isotherm is used to explain how adsorbates interact with adsorbents and to optimize the adsorbents dosage. Therefore finding out a suitable model of isotherms data was a must and this was done by fitting them to different isotherm models (Jianlong et al., 2001). The effect of material dosage concentration was monitored in a batch mode experiments at the adsorption equilibrium time of $240 \mathrm{~min}$ in order to study the equilibrium sorption of BR 46 dye onto the prepared PAN nanoparticles. The isotherm data gained from this study were fitted to the Langmuir and Freundlich isotherms.

The adsorption equilibrium of BR 46 onto the prepared PAN nanoparticles as adsorbent material was investigated by Langmuir equation. Langmuir isotherm model assumes monolayer coverage and uniform activity distribution on the adsorbent surface. Figure 11 indicates a straight line with high correlation coefficient value $\left(\mathrm{R}^{2}=0.98\right)$ for the linearized plot of the equation that is expressed as:

$$
\frac{C_{e}}{q_{e}}=\frac{1}{q_{m} K}+\frac{C_{e}}{q_{m}}
$$

Where $q_{e}$ is the amount of adsorbed dye $(\mathrm{mg} / \mathrm{g}), C_{e}$ is the equilibrium concentration of the adsorbate ions $(\mathrm{mg} / \mathrm{L})$, and $q_{m}$ and $\mathrm{K}$ are Langmuir constants related to maximum adsorption capacity (monolayer capacity) $(\mathrm{mg} / \mathrm{g}$ ) and energy of adsorption $(\mathrm{L} / \mathrm{mg})$, respectively. Therefore, the Langmuir isotherm model can describe Basic Red 46 dye sorption onto PAN nanoparticles. As Langmuir isotherm model supposes a monolayer coverage and uniform activity distribution on the adsorbent surface, it was more appropriate to explain the experimental data compared with Freundlich isotherm model. Langmuir parameters for Basic Red 46 dye removal $\left(q_{m}\right.$ and $\mathrm{K})$, were calculated and tabulated at Table 1 . The calculated value of monolayer adsorption capacity $q_{m}$ is equal to $200 \mathrm{mg}$ of BR 46 dye/g of the PAN nanoparticles. It was concluded that the prepared PAN material is appropriate for Basic Red 46 dye removal with energy of sorption equal to 0.189 $\mathrm{mg} / \mathrm{L}$

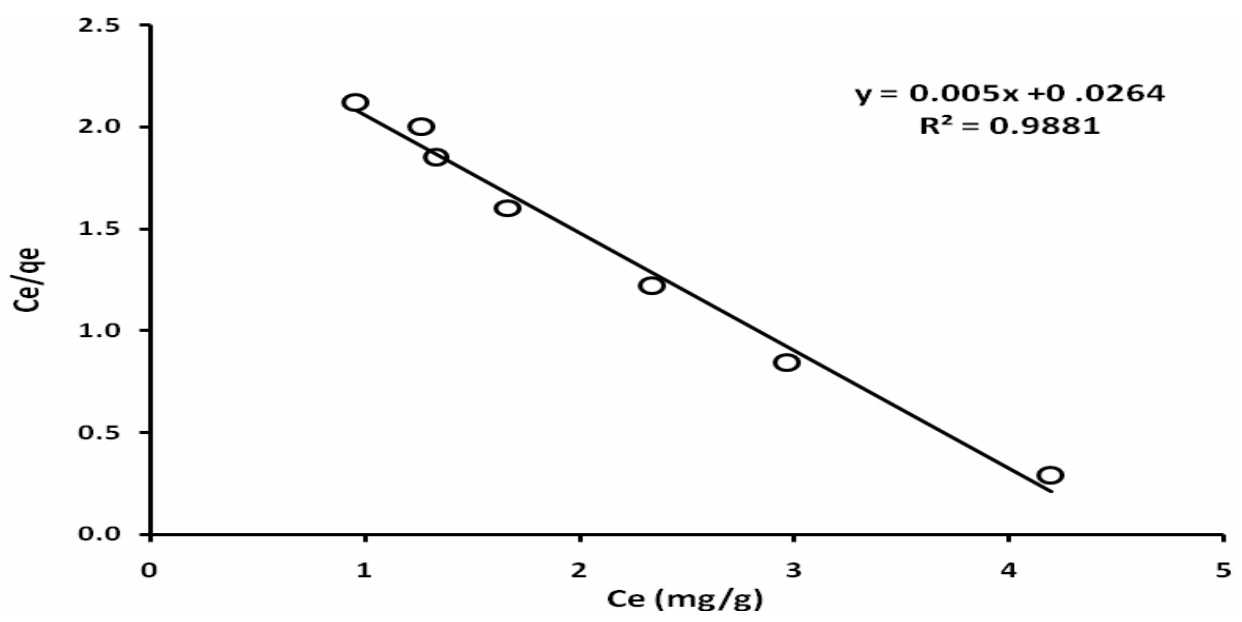

Figure 11: Langmuir Adsorption Isotherm onto PAN Material.

The Freundlich isotherm doesn't describe the monolayer sorption capacity in contrast to the Langmuir model (Mohy Eldin et al., 2010). Freundlich isotherm model supposedly heterogeneous site energies and no limited levels of sorption. It has been shown to be reliable with the exponential distribution of active centers, which is characteristic of heterogeneous surfaces (Bayramoglu and Arica, 2013).

The linearized form of the Freundlich equation may be expressed as:

$$
\ln q_{e}=\ln K_{F}+\frac{1}{n_{f}} \ln C_{e}
$$

where $\mathrm{q}_{\mathrm{e}}$ is the amount of dye adsorbed at equilibrium $(\mathrm{mg} / \mathrm{g}) ; \mathrm{C}_{\mathrm{e}}$ is the equilibrium concentration of the adsorbate $(\mathrm{mg} / \mathrm{L})$; and $\mathrm{K}_{F}$ and $n_{\mathrm{f}}$ are Freundlich constants related to the adsorption capacity and adsorption intensity, respectively. Figure 12 indicates a straight line with low value of the correlation coefficient $\left(\mathrm{R}^{2}=0.95\right)$ for the linearized plot of the equation compared with the Langmuir correlation coefficient. Roughly, the intercept of the line, KF, indicates adsorption capacity، and slope, n, indicates adsorption effectiveness. Freundlich parameters for Basic Red 46 dye removal $\left(q_{m}\right.$ and $\mathrm{K})$ were tabulated at Table 1 . It was found that $\mathrm{n}_{\mathrm{f}}<1$ indicated that the dye sorption process onto the prepared PAN nanoparticles was not favorable. Accordingly, dye sorption 
process onto PAN material obey Langmuir isotherm. As Langmuir isotherm model supposes a monolayer coverage and symmetrical activity division on the materials surfaces. So it can be predicted that the Langmuir model was suitable to analyses the experimental data compared with Freundlich isotherm model.

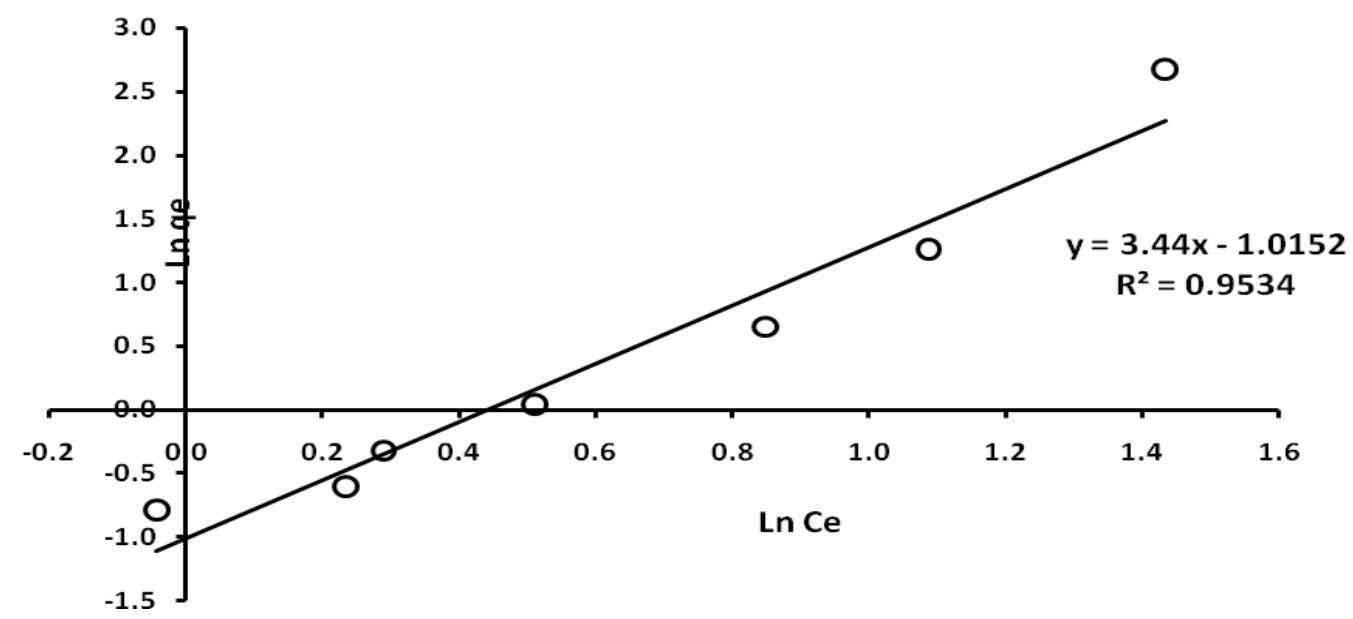

Figure 12: Freundlich Adsorption Isotherm onto PAN Material.

Table 1: Estimated Equilibrium Parameters for Dye Adsorption onto PAN Material.

\begin{tabular}{c|c|c|c|c|c}
\hline \multicolumn{5}{c}{ Equilibrium isotherm } \\
\hline \multicolumn{3}{c}{ Langmuir constant } & & \multicolumn{3}{c}{ Freundlich constant } \\
\hline $\mathbf{q}_{\mathbf{m}}(\mathbf{m g} / \mathbf{g})$ & $\mathbf{K}_{\mathbf{L}}(\mathbf{L} / \mathbf{m g})$ & $\mathbf{R}^{2}$ & $\mathbf{K}_{\mathbf{F}}(\mathbf{m g} / \mathbf{g})$ & $\mathbf{n}_{\mathbf{F}}$ & $\mathbf{R}^{2}$ \\
\hline 200 & 0.189 & 0.9889 & 2.759 & 0.29 & 0.953 \\
\hline
\end{tabular}

\subsection{Kinetic Models of Dye Adsorption Process}

The dye removal rate from the aqueous solution by solid sorbents is essential to evaluate the adsorption kinetics using theoretical models in order to design and control the sorption process units. Therefore, studying the adsorption kinetics of a material is so important, as it gives information about the adsorption mechanism. Moreover, it helps in choosing the appropriate kinetic model (Elkady et al., 2015). Owing to control and design the sorption process units, the pseudo firstorder and pseudo-second-order models were applied to investigate the adsorption of Basic red 46 dye onto the prepared PAN nanoparticles.

The Lagergren first-order equation is given as :

$$
\ln \left(q_{e}-q_{t}\right)=\ln q_{e} k_{1} t
$$

where $q_{e}$ and $q_{t}$ are amounts of dye ions sorbed $(\mathrm{mg} / \mathrm{g})$ at equilibrium and at time $\mathrm{t}(\mathrm{min})$, respectively. $k_{1}\left(\mathrm{~min}^{-1}\right)$ is the first-order reaction rate constant (Figure 13). If the pseudofirst order kinetics is applicable to the experimental data, a plot of $\ln \left(q_{e}-q_{t}\right)$ versus $t$ should present a linear relationship as shown in Figure 12,which investigated low $R^{2}$ value that recorded as 0.5076 for PAN. Also, the estimated values of $\mathrm{q}_{\mathrm{e}}$ calculated with the equation, differed from the experimental values, (calculated $=0.532 \mathrm{mg} / \mathrm{g}$ for $\mathrm{PAN}$, experimental $=1.320$ $\mathrm{mg} / \mathrm{g}$ ) for PAN, so, the first-order kinetic model was not appropriate to describe the sorption process for the prepared PAN nanoparticles.

The kinetic data were further analyzed using the pseudo second-order model expressed as:

$$
\frac{t}{q_{e}}=\frac{1}{k_{2} q_{e^{2}}{ }^{2}}+\left(\frac{t}{q_{e}}\right)
$$




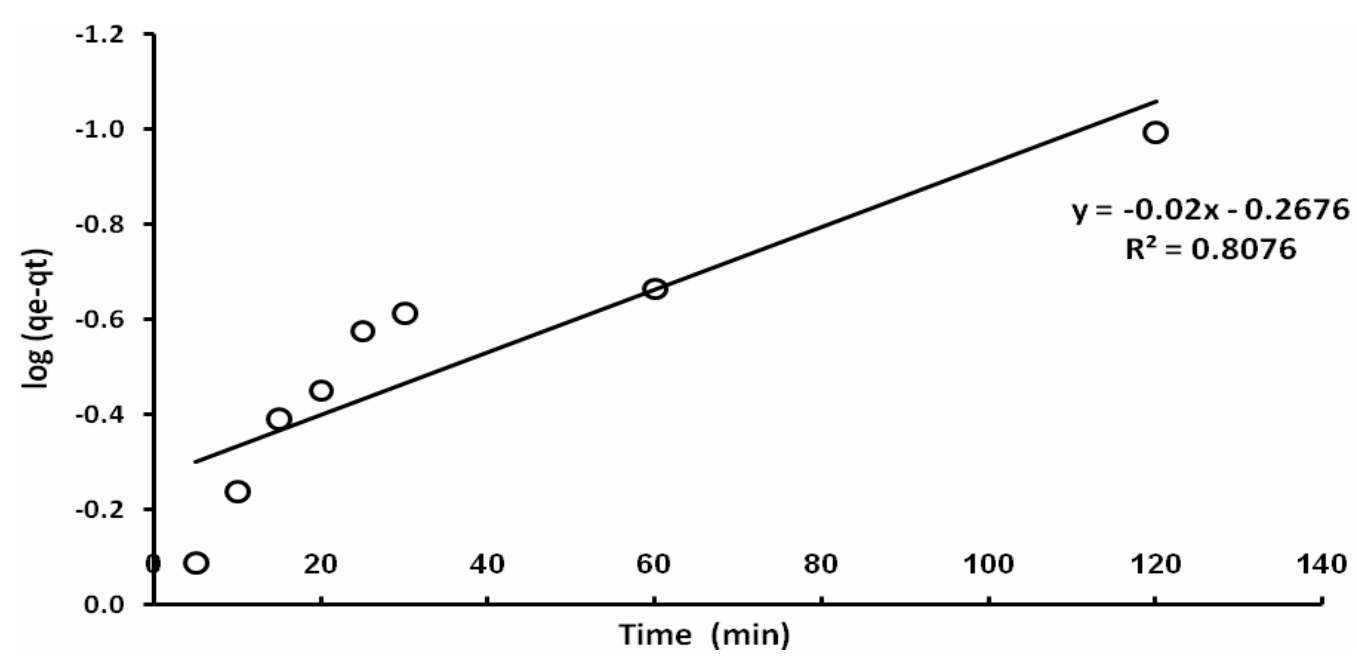

Figure 13: Pseudo-first-order kinetics for adsorption of Basic Red 46 onto PAN Material.

where the equilibrium adsorption capacity $\left(\mathrm{q}_{\mathrm{e}}\right)$, and the pseudo second-order constants $\mathrm{k}_{2}$ ( $\mathrm{g} /(\mathrm{mg} \min )$ ) can be determined experimentally from the slope and intercept of plot $\mathrm{t} / \mathrm{q}_{\mathrm{t}}$ versus $\mathrm{t}$ (Figure 14). The model fits the kinetic date very well as $\mathrm{R}^{2}$ has very high value $\left(\mathrm{R}^{2}=0.990\right)$. The kinetics of Basic Red 46 sorption onto PAN material could be explained well with a second order equation. Results suggest that the rate-limiting step in these adsorption processes may be chemisorptions involving valent forces. Additionally, comparison of the calculated values of $\mathrm{q}_{\mathrm{e}}$ that resulted from the intersection points of the second-degree reaction kinetic curve (14) with those obtained from the experimental data (Table 2) was performed. It was indicated that the true values were approximately equivalent. So, the second- order rate expression fit the experimental data most adequately

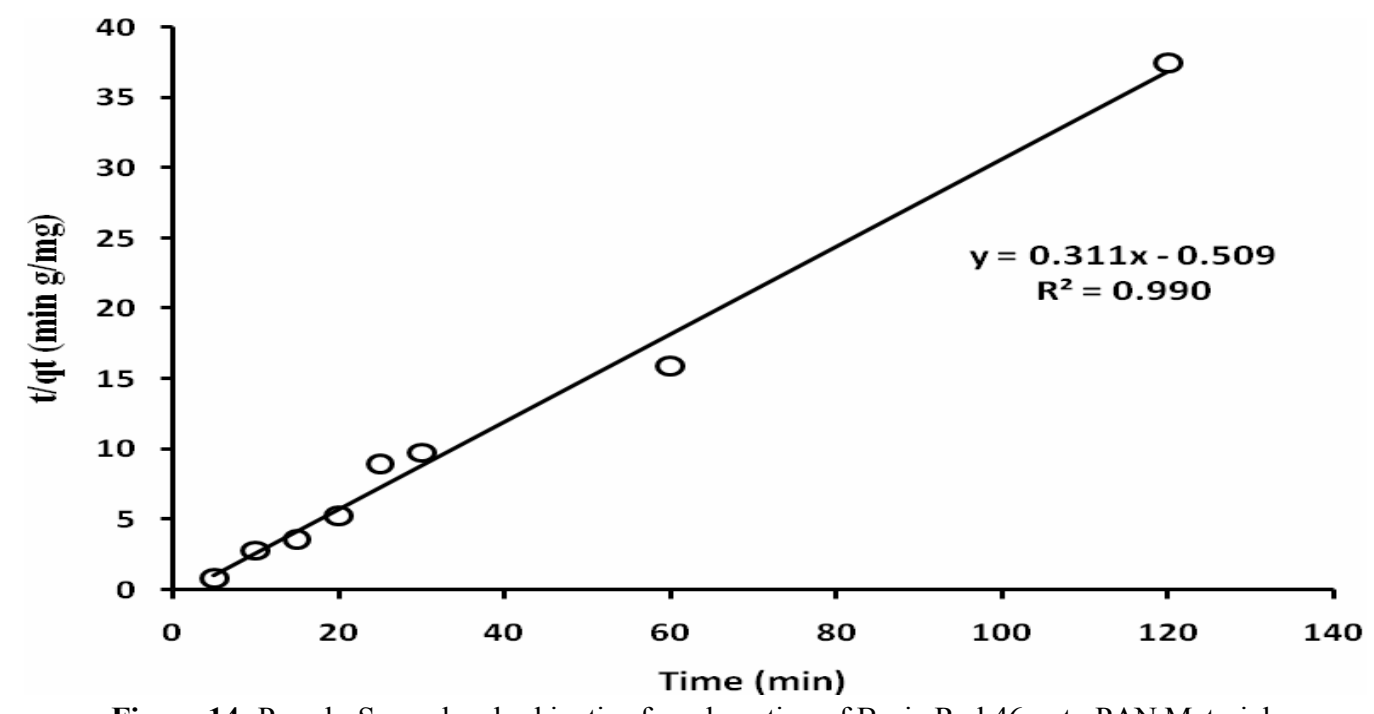

Figure 14: Pseudo-Second-order kinetics for adsorption of Basic Red 46 onto PAN Material.

Table 2: Kinetic parameters of dye adsorption onto PAN Material.

\begin{tabular}{ccccccccc}
\hline \multicolumn{2}{c}{ Kinetic model } & \multicolumn{3}{c}{ Pseudo-first order } & \multicolumn{4}{c}{ Pseudo-second order } \\
\hline $\begin{array}{c}\text { Dye concentration } \\
(\mathbf{m g} / \mathbf{L})\end{array}$ & $\begin{array}{c}\left(\mathbf{q}_{\mathbf{e}}\right)_{\mathrm{exp}} \\
(\mathbf{m g} / \mathbf{g})\end{array}$ & $\begin{array}{c}\left(\mathbf{q}_{\mathrm{e}}\right)_{\mathrm{eal}} \\
(\mathbf{m g} / \mathbf{g})\end{array}$ & $\begin{array}{c}\mathbf{K}_{\mathbf{1}} \\
\left(\mathrm{min}^{-1}\right)\end{array}$ & $\mathbf{R}^{2}$ & $\begin{array}{c}\left(\mathbf{q}_{\mathbf{e}}\right)_{\mathbf{e x p}} \\
(\mathbf{m g} / \mathbf{g})\end{array}$ & $\begin{array}{c}\left(\mathbf{q}_{\mathbf{e}}\right)_{\mathrm{cal}} \\
(\mathbf{m g} / \mathbf{g})\end{array}$ & $\begin{array}{c}\mathbf{K}_{\mathbf{2}} \\
(\mathbf{g} / \mathbf{m g} \\
\mathbf{m i n})\end{array}$ & $\mathbf{R}^{\mathbf{2}}$ \\
\hline 5 & 1.320 & 0.532 & 0.02 & 0.8076 & 3.211 & 2.936 & 0.6108 & 0.990 \\
\hline
\end{tabular}




\section{Conclusion}

PAN nanoparticles had been prepared through precipitation polymerization technique, its ability as adsorbant material for the removal of acationic dye (Basic Red 46) from a polluted water samples had been studied. The prepared material morphological structure had been investigated through SEM images; also, TGA and FT-IR have also applied. The experimental results proved that the improvement in material dosage from 0.025 to $0.5 \mathrm{~g}$ enhanced the dye removal percentage as it increased from $43 \%$ to $85 \%$. Meanwhile, the increment in initial dye concentrations had negative impact on the dye sorption process, as the removal decreased from $82.8 \%$ to $11.8 \%$ when the initial dye concentration increased from 1-100 ppm. The equilibrium isotherm models applicability of dye adsorption onto the prepared PAN nanoparticles had been studied and its results prevailed that the dye adsorption occurred onto PAN surface as monolayer coverage. Also, the kinetics of dye adsorption rate was expressed well by the pseudo-second order kinetic equation which suggested that the main adsorption mechanism was chemisorption process. This study concluded that the prepared PAN nanoparticles could be used as an adsorbate for the removal of different cationic dye pollutants from aquatic environments.

\section{References}

Abu-Saied, M.; Abdel-Halim, E.; Fouda, M.; Al-Deyab, S. (2013). Preparation and Characterization of Iminated Polyacrylonitrile for the Removal of Methylene Blue from Aqueous Solutions. International Journal of Electrochemical Science 8, $5121-5135$.

Aksakala, O.; Ucun, H. (2010). Equilibrium, kinetic and thermodynamic studies of the biosorption of textile dye (Reactive Red 195) on to Pinussylvestris. L. Journal of Hazardous Materials, 181, 666-672.

Al-Qodah, Z. (2000): Adsorption of dyes using shale oil ash. Water Research 34; 17, 4295-4303.

Alkan, M. and Dogan, M. (2003): Adsorption kinetics of Victoria blue onto perlite, Fresen. Environ. Bull. 12, 418-425.

Araujo, M.M.; Teixeira, J.A. (1997). Trivalent chromium sorption on alginate beads. International Bio deterioration and Biodegradation, 40, 63-74.

Bayramoglu, G. and Arica, M. Y. (2013). Removal of reactive dyes from wastewater by acrylate polymer beads bearing amino groups: isotherm and kinetic studies Publication cover image. Coloration Technol , 129, (2), 114-124

Coats, A.; Redfern, J. (1963). Thermogravimetric analysis. A review. Analyst, 906-924.

Crini, G.; Badot, P.M. (2008). Application of chitosan, a natural amino polysaccharide, for dye removal from aqueous solutions by adsorption processes using batch studies: a review of recent literature, Progress in Polymer Science, 33 (4), 399-447.
Deniz, F. and Karaman, S. (2011). Removal of Basic Red 46 dye from aqueous solution by pine tree leaves. Chemical Engineering Journal, 170, 67-74.

El-Aassar, M. R. (2013). Functionalized electro spun nanofibers from poly (AN-co-MMA) for enzyme immobilization. Journal of Molecular Catalysis B: Enzymatic, 85, 141-148.

EL Alouani, M.; Alehyen, S.; EL Achouri, M.; Taibi, M.; (2018). Removal of Cationic Dye - Methylene Bluefrom Aqueous Solution by Adsorption on Fly Ashbased Geopolymer. Journal of Materials and Environmental Sciences, 9, 1, 32-46.

El Haddad, M.; Mamouni, R.; Saffaj, N.; Lazar, S. (2012). Removal of a cationic dye -Basic Red 12- from aqueous solution by adsorption onto animal bone meal. Journal of the Association of Arab Universities for Basic and Applied Sciences, 12, 48-54.

Elkady, M.F.; Hussien, M.; Abou-rady, R. (2015). Equilibrium and kinetics behavior of oil spill process onto synthesized nano-activated carbon. American Journal of Applied Chemistry, 3, 22-30.

El-Kady, M.; El-Aassar, M.R.; El Batrawy, O.; Ibrahim, M.; Hassan, H.; Fakhry, H. (2018). Equilibrium and Kinetic Behaviors of Cationic Dye Decolorization Using Poly (AN-co-Py) $/ \mathrm{ZrO}_{2}$ Novel Nanopolymeric Composites. Advances in Polymer Technology, 37(3), DOI 10.1002/adv.21716.

Gorza, F.; Pedro, G.; Da Silva, R.; Medina-Llamas, J.C.; Alcaraz-Espinoz, J.J.; Chávez-Guajardo, A.E.; DeMelo, C.P. (2017). Electrospun polystyrene (emeraldine base) mats as high-performance materials for dye removal from aqueous media. Journal of the Taiwan Institute of Chemical Engineers, 82 https://doi.org/10.1016/j.jtice.2017.10.034

Hadi, A. (2013): Dye Removal from Colored Textile Wastewater Using Synthesized Chitosan. International Journal of Science and Technology 2; 4.

Haider, S.; Binagag, F., Haider, A.; Al- Masry, W. (2014). Electrospun oxime-grafted-poly acrylonitrile nanofiber membrane and its application to the adsorption of dyes. Journal of Polymer Research, 21:371.

Hameed, B. and Ahmad, A. (2009). Batch adsorption of methylene blue from aqueous solution by garlic peel, an agricultural waste biomass, J. Hazar. Mater. 164, 870-875.

Han, S.; Liu, K.; Hu, L.; Teng, F.; Yu, P.; Zhu, Y. (2017). Superior Adsorption and Regenerable Dye Adsorbent Based on Flower-Like Molybdenum Disulfide Nanostructure. Scientific Reports, 7:43599, DOI: $10.1038 /$ srep43599.

Hu, L.; Yang, Z.; Wang, Y.; Li, Y.; Fan, D.; Wu, D.; Wei, Q.; $\mathrm{Du}, \mathrm{B}$. (2017). Facile preparation of water soluble hyper branched polyamine functionalized multi walled carbon nanotubes for high-efficiency organic dye removal from aqueous solution. Scientific Reports 7:3611, DOI:10.1038/s41598-017-03490-6. 


\section{Journal of Environmental Sciences, 2018; Vol. 47, No. 3-4 : 75-87}

Ibrahim, G.P.; Isloor, A.M.; Inamuddin; Asiri, A.M.; Ismail, N.; Ismail, A.M.; Ashraf, G.M. (2017). Novel, onestep synthesis of zwitterionic polymer nanoparticles via distillation-precipitation polymerization and its application for dye removal membrane. Scientific Reports, 7:15889, DOI:10.1038/s41598-017-16131-9.

Janaki, V.; Vijayaraghavan, K.; Byung-Taek, O.; Ramasamy, A. K.; Kamala-Kannan, S. (2012). Synthesis, characterization and application of cellulose/polyaniline nanocomposite for the treatment of simulated textile effluent. Cellulose, 20, 1153-1166.

Jianlong, W.; Xinmin, Z.; Decai, D.; Ding, Z. (2001). Bioadsorption of Lead (II) from Aqueous Solution byFungal Biomass of Aspergillus niger, Journal of Biotechnology, 87 (3), 273-277.

Kalavathy, M.H. and Miranda, L.R. (2010): Comparison of copper adsorption from aqueous solution using modified and unmodified Hevea brasiliensis saw dust. Desalination 255, 165- 174.

Kaouah, F.; Boumaza, S.; Berrama, T.; Trari, M.; Bend jama, Z. (2013). Preparation and characterization of activated carbon from wild olive cores (oleaster) by $\mathrm{H}_{3} \mathrm{PO}_{4}$ for the removal of Basic Red 46. Journal of Cleaner Production, 54, 296-306.

Karim, A.B.; Mounir, B.; Hachkar, M.; Bakasse, M. and Yaacoubi, A. (2009) Removal of Basic Red 46 dye from aqueous solution by adsorption onto Moroccan clay. Journal of Hazardous Materials, 168, 304-309.

Lou,T.; Cui, G.; Xun, J.; Wang, X.; Feng, N.; Zhang, J. (2018). Synthesis of a terpolymer based on chitosan and lignin as an effective flocculant for dye removal., Colloids and Surfaces A: Physicochemical and Engineering Aspects, 537, 149- 154, https://doi.org/10.1016/j.colsurfa.2017.10.012

Luo, X.P.; Fu, S.Y.; Du, Y.M.; Guo, J.Z.; Li, B. (2016). Adsorption of methylene blue and malachite green from aqueous solution by sulfonic acid group modified MIL-101. Microporous and Mesoporous Materials, 237, doi: 10.1016/j.micromeso.2016.09.032.

Mahmoodi, N.; Najafi, F.; Khorramfara, S.; Aminia, F. and Aramic, M. (2011): Synthesis, characterization and dye removal ability of high capacity polymeric adsorbent: Polyaminoimide homopolymer. Journal of Hazardous Materials 198, 87-94.

Mohy Eldin, M.; Elkady, M. F.; Abu-Saied, M.; Abdel Rahman, A.; Soliman, E.; Elzatahry, A.; Youssef, M. (2010). Removal of Cadmium Ions from Synthetic Aqueous Solutions with a Novel Nanosulfonated Poly (glycidylmethacrylate) Cation Exchanger: Kinetic and Equilibrium Studies, Journal of Applied Polymer Science, 118, 3111-3122.
Musale, D.; Kumar, A. (2000). Effects of surface crosslinking on sieving characteristics of chitosan/poly (acrylonitrile) composite nanofiltration membranes. Separation and Purification Technology, 21, 27 - 38.

Prachi, Gautam P.; Madathil, D. and Brijesh, Nair A. (2013): Nanotechnology in Waste Water Treatment: A Review. International Journal of Chem Tech Research 5, 2303-2308.

Salama, A. (2017). New sustainable hybrid material as adsorbent for dye removal from aqueous solutions, Journal of Colloid and Interface Science. 487, 348353, doi: http://dx.doi.org/10.1016/j.jcis.2016.10.034

Sarioglu, M.; Bali, U.; Bisgin, T. (2007). The removal of C.I. Basic Red 46 in a mixed methanogenic anaerobic culture. Dyes and Pigments, 74, 223-229.

Satapanajaru, T.; Chompuchan, C.; Suntornchot, P. and Pengthamkeerati, P. (2011): Enhancing decolorization of Reactive Black 5 and Reactive Red 198 during nano zerovalent iron treatment. Desalination 266, 218-230.

Sharma, K.; Sharma, S.; Sharma, S., Singh, P.; Kumar, S.; Grover, R. and Sharma, p. (2007): A comparative study on characterization of textile wastewaters (untreated and treated) toxicity by chemical and biological tests. Chemosphere 69, 48-54.

Srivastava, V.C.; Swamy, M.M.; Mall, I.D.; Prasad, B. and Mishra, I.M. (2006): Adsorptive removal of phenol by bagasse fly ash and activated carbon: equilibrium, kinetics and thermodynamics. Colloids and Surfaces A: Physicochemical and Engineering Aspects 272, 89104.

Srivastava, V.C.; Mall, I.D.; and Mishra, I.M. (2008): Removal of cadmium (II) and zinc (II) metal ions from binary aqueous solution by rice husk ash. Colloids and Surfaces A: Physicochemical and Engineering Aspects 312, $172-184$.

Sun, Y.; Li, X.; Cao, J.; Zhang, W. and Wang, H. (2006): Characterization of zero-valent iron nanoparticles. Advances in Colloid and Interface Science 120, 4756.

Tiwari, D.; Singh, S. and Sharma, N. (2014): Sorption of methylene blue on treated agricultural adsorbents: equilibrium and kinetic studies. Applied Water Science $5 ; 1,81-88$.

Wua, T.; Cai, X.; Tan, S.; Li, J. and Yang, W. (2011): Adsorption characteristics of acrylonitrile, ptoluenesulfonic acid, 1-naphthalenesulfonic acid and methyl blue on graphene in aqueous solutions. Chemical Engineering Journal, 173, 144-149. 


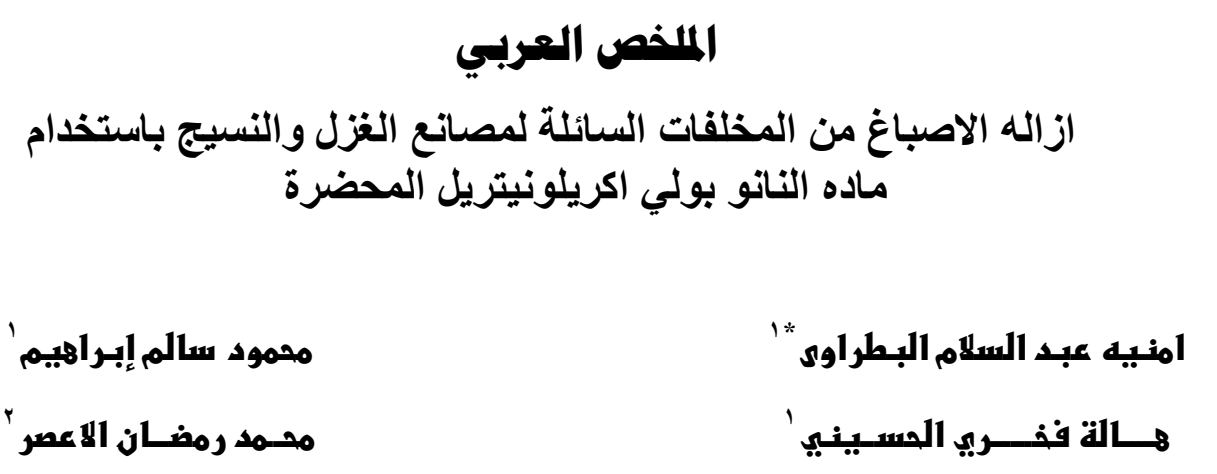

'قسم العلوم البييئه ـ كليه العلوم - جامعه دمياط ـ مدينه دمياط الجديده ـ دمياط ـ مصر.

كتسم بحوث البوليمر اتـ معهد بحوث التكنولوجيـا المتقدمه و المـواد الجديدة ـ ـ الهيئة العامـة لمدينة

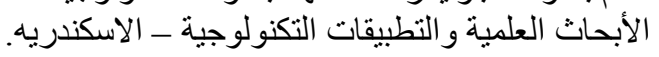

يعتبر تلوث المياه من أهم ملوثات البيئه وذلك لان ناثيره السلبى لايقتصر فقط على الاضرار بصحه الانسان و البيئه بل

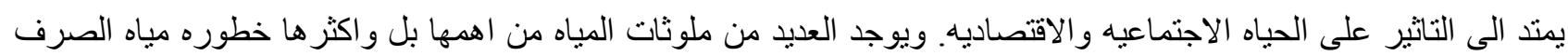
الناتجه من صناعات الغزل و النسيج وذللك لانها عباره عن خليط من الاصباغ و الملوثات العضويه والاملاح الكليه الذائبه. تقدم تقنية النانو مواد جديدة في مجال معالجة مياه الصرف الصحي وخاصة إزالة الصبغة، حيث تعتبر جزيئات البولي اكريلونيتريل النانوية واحدة من أكثر المواد الواعده في مجال إزالة الصبغة. تم تحضير جزيئات PAN (PAN) الترسيب فى وسط مائى كحولى، وتم توصيفها توصيفا كاملا باستخدام الميكروسكوب الالكترونى SEM ، التحليل الحرارى TGA و التحليل باستخدام FT-IR. فى هذه الدراسه تم استخدام صبغه (BR 46) و هى صبغه موجبه الثحنه وتم استخدامها كنموذج ملوث للمياه وذلك لكثره استخدامها فى صناعه الغزل و النسيج، كما تم در اسه العو امل المؤثره على از اله الصبغه باستخدام جزيئات البولي اكريلونيتريل من خلال تجارب batch mode experiments. ولقد اوضحت النتائج المعطليه ان اقصى نسبه

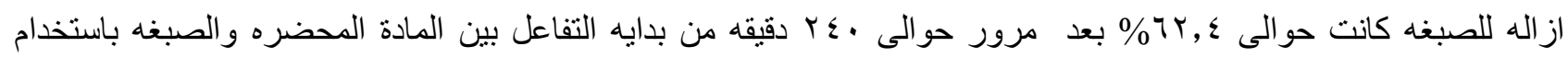

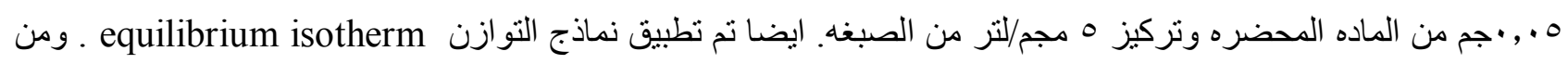
خلال النتائج السابقه يتضح مدى فاعليه الماده المحضره PAN فى از اله الاصباغ الناتجه من صناعه الغزل و النسيج. 


\section{Journal of Environmental Sciences}

\section{JOESE 5}

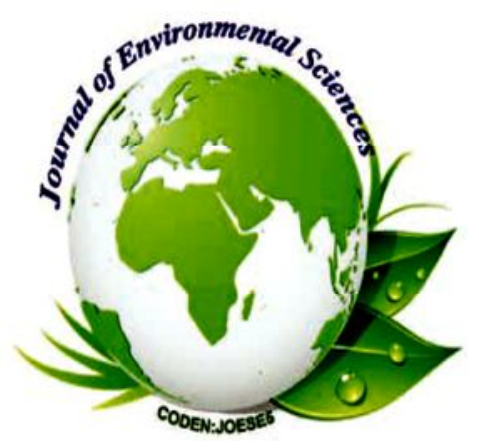

\section{Decolorization of Textile Wastewater Using Fabricated Poly Acrylonitrile (PAN) Nanoparticles}

\footnotetext{
Omnya A. El-Batrawy ${ }^{1 *}$, Mahmoud S. Ibrahim ${ }^{1}$, Hala Fakhry ${ }^{1,2}$ and M. R. El-Aassar ${ }^{2}$

${ }^{1}$ Environmental Sciences Department, Faculty of Science, Damietta University, New Damietta City, Damietta, 34517, Egypt.

${ }^{2}$ Polymer Materials Research Department, Advanced Technology and New Materials Researches Institute, City of Scientific Researches and Technological Applications, New Borg El-Arab City, Alexandria, 21934 Egypt.
}

\section{Reprint}

Volume 74, Number 3-4 : 75 -87

(2018) 